\title{
Estudo da percepção ambiental como ferramenta de sensibilização à redução da caça de animais silvestres na Reserva Florestal Mata de Cazuzinha, Cruz das Almas-BA
}

Study of environmental perception as awareness tool for the reduction of the hunting wild animals in the Mata de Cazuzinha Forest Reserve, Cruz das Almas-BA

\author{
Divaney Mamédio', \\ Adevan da Silva Pugas", \\ Jesus Manuel Delgado Mendez"II
}

\section{Resumo}

Objetivou-se avaliar a percepção ambiental dos moradores do entorno da Reserva Florestal Mata de Cazuzinha, na cidade de Cruz das Almas, BA, relativo às questões de caça nessa área protegida. O foco da pesquisa foi centralizado na entrevista de 32 moradores do entorno desta área, a qual permitiu avaliar a percepção dos mesmos em relação à caça, mediante a observação de campo e aplicação de questionários e entrevistas semiestruturados. Os resultados permitem apontar uma redução drástica das atividades referentes a caça e captura de animais na reserva. Aproximadamente metade da comunidade acredita que os responsáveis por essas atividades sejam os jovens e adultos. A diversão foi apontada como ser a causa principal de caçar animais na mata, e mesmo não sendo a favor desta, uma significativa parcela da amostra justifica essa atividade quando se mostrar necessária à sobrevivência da família. No que tange à legalidade desta prática, a maioria dos moradores caracterizam a caça como ato ilegal. Conclui-se que a falta de supervisão e fiscalização que reprima a destruição de habitats e a insuficiência das abordagens da educação ambiental, evidencia necessidade de maiores investimentos por parte do poder público para a preservação da fauna e demais recursos naturais.

Palavras-chave: Captura animal; Consciência ambiental; Preservação ambiental

\section{Abstract}

The study aimed to evaluate the environmental perception of dweelers around the Mata de Cazuzinha Forest Reserve, in the town of Cruz das Almas, Bahia, Brazil, in relation to the hunting process in the protected area. The focus of this research was centralized on 32 community members living around the area, which allowed to evaluate their perception about hunting, through field observation and semi structured interviews and questionnaire. The results point out to the non-promotion of hunt or capture activities. About half the community believes that adults and young people are among the responsible for this activity. Pleasure is pointed out as the main cause for killing animals in the forest, but even though they are not in favor of hunting, a considerable parcel of the interviewed are in favor of hunting for family survival. Considering the legal aspects of this activity, most of the people considered hunting as an illegal act. It is concluded that the lack of supervision and control that represses the destruction of habitats and the insufficiency of the approaches of environmental education, evidences the need for greater investments by the public power for the preservation of fauna and other natural resources.

Keywords: Animal capture; Environmental awareness; Environmental preservation

I Universidade Estadual de Maringá, Maringá, Brasil - divaney.zootecnia@gmail.com

II Universidade Federal de Santa Catarina, Brasil - vanpugas1@hotmail.com

III Universidade Federal do Recôncavo da Bahia - jesus@ufrb.edu.br 


\section{Introdução}

A sociedade abordou as questões ambientais de maneira irrelevante por muito tempo. Dados históricos revelam que as diversas ações predatórias concretizadas pelo homem no decorrer dos séculos, geraram inúmeros problemas ao meio ambiente, devido à forma desordenada como estes recursos naturais vêm sendo utilizados.

A busca pela sobrevivência, fez com que o homem provocasse uma onda de transformações no meio em que vivia a partir dos conhecimentos produzidos, promovendo assim, durante sua trajetória histórica, um desequilíbrio nas relações homem/natureza, na qual o homem se enxergava com uma visão antropocêntrica, se sentindo, portanto, superior à natureza. Com tudo esse pensamento excludente causa uma visão equivocada, pois tudo o que este faz ao meio o atinge de alguma maneira, já que a humanidade jamais existiu isolada do resto da vida.

Diante desses problemas, se faz importante uma educação ambiental que leve ao aumento da consciência da coletividade, de forma que a mesma possa construir conhecimentos, valores sociais, habilidades, atitudes, competências e ações responsáveis voltadas para a conservação do meio ambiente. A partir de estudos mais detalhados sobre a percepção ambiental dos grupos diretamente envolvidos, é possível planejar e executar ações com bases in loco, focada nas vivências de cada indivíduo e a sua percepção do entorno, quer dizer, do meio o qual está inserido, bem como os seus sentimentos, sejam eles positivos ou negativos com relação ao lugar (FAGGIONATO, 2007).

Silva et al. (2016) se refere à percepção ambiental como um processo principalmente cognitivo, estabelecido a partir de mecanismos perceptivos, voltados à captação dos sentidos oriundos das inter-relações indivíduo/ambiente. Partindo desse ponto de vista, Del Rio (1999) concluiu que a percepção do indivíduo com relação ao seu entorno, passa a ser subjetiva. Dessa forma, se permite a observação de que a percepção ambiental de cada ser individual, está permeada por todas as suas vivências e culturalidade, assim como pontuado nos estudos de Costa e Colesanti (2011). No que tange à cultura, Geertz (1989, p.15) refere-se à cultura como sendo a composição de todos acontecimentos e, nesse sentido, ressalta: “o homem é um animal amarrado a teias de significados que ele mesmo teceu".

Costa e Colesanti (2011) ressaltaram que tais estudos voltados à esta temática, está fundamentado na sensibilidade do entendimento de que a percepção não parte do coletivo, mas, sim, da individualidade de cada ser, aliado ao conjunto de sentimento e valores, responsáveis por toda e qualquer atitude que venha a orientar as ações deste nos espaços aos quais está inserido. Por essa razão, Costa e Colesanti afirmaram que a percepção é uma análise fundamental em estudos relacionados à áreas verdes, principalmente afim de se compreender as relações dos indivíduos com estes espaços.

Em análise mais completa, Tuan (1980) aborda o seu entendimento sobre percepção com sendo

a resposta dos sentidos aos estímulos externos, como a atividade proposital, na qual certos fenômenos são claramente registrados, enquanto outros retrocedem para a sombra ou são bloqueados. Muito do que percebemos tem valor para nós, para a sobrevivência biológica, e para propiciar algumas satisfações que estão enraizadas na cultura (p. 5).

Com base na abordagem supracitada, esse estudo busca debater e entender as inter-relações entre a comunidade e a Reserva Florestal Mata de Cazuzinha e todas as implicações ocasionadas, principalmente, por já se ter constatado em literatura científica que historicamente a área de mata, até a sua conversão em reserva legal, sofreu grande redução de seu tamanho, devido ao crescimento desordenado da cidade que a rodeia, assim como o constatado nos trabalhos de Silva et al. (2016) e Nascimento e Souza (2010), em que esses estudiosos enfatizaram que a expansão urbana acelerada ocasionou impactos negativos ao ambiente circunjacente, com graves desequilíbrios e efeitos nocivos à própria comunidade causante deste.

A Mata de Cazuzinha representa um fragmento de 13 ha de mata atlântica dentro do município de Cruz das Almas- BA. Sendo instituído como Reserva Florestal em cinco de junho de 2009. Afirma-se que a Mata de Cazuzinha representa um importante reduto de Mata Atlântica do Recôncavo da Bahia, em meio à área urbana do município de Cruz das Almas. No entanto, esse patrimônio ainda assim se encontra ameaçado devido à expansão habitacional e do desmatamento ilegal, fatores que refletem negativamente nos componentes biológicos do ecossistema e suas interações (SIMÕES; SILVA; MARTINS, 2013).

Segundo Rocha e Costa (1998), o bioma em questão está em extremo estado de degradação, sendo que, do território original, apenas de sete a $8,5 \%$ ainda se apresenta de alguma forma preservada. Assim, um bioma que ocupara um dia a parte do território nacional mais próximo ao litoral brasileiro, sofreu degradação evidente desde o descobrimento do país até os dias de hoje.

Entre todos os impactos que afetaram esse importante bioma brasileiro, a caça ilegal e indiscriminada é um dos fatores que orientam este trabalho. Sabe-se que a caça contribui significativamente para a chamada erosão biológica em ecossistemas como este. Seja para a alimentação de famílias do entorno das matas, ou até mesmo com fim de recreação, a caça indiscriminada favorece a diminuição da população animal dos fragmentos de mata atlântica ainda existente.

Por tanto, fica evidente a necessidade de se realizar projetos e atividades que busquem promover a sensibilização da população acerca da preservação desses animais, além de levantamentos sobre o hábito de caça da população do entorno deste fragmento de Mata Atlântica. Nesse sentido, a finalidade do presente trabalho é avaliar a percepção ambiental dos moradores do entorno da Reserva Florestal Mata de Cazuzinha relativo às questões de caça nessa área protegida.

\section{Metodologia}

\subsection{Caracterização da área de estudo}

O município de Cruz das Almas está inserido na região do Recôncavo da Bahia ( $12^{\circ} 40^{\prime} 19^{\prime \prime}$ S e $39^{\circ} 06^{\prime} 23^{\prime}$ 'W) e possui 64.552 habitantes (IBGE, 2016). Este estudo foi desenvolvido no entorno da Reserva Florestal Mata de Cazuzinha, área de resquícios do Bioma Mata Atlântica, 
Figura 1 - Mapa da Cidade de Cruz das Almas - BA, com destaque para Reserva Florestal Mata de Cazuzinha.

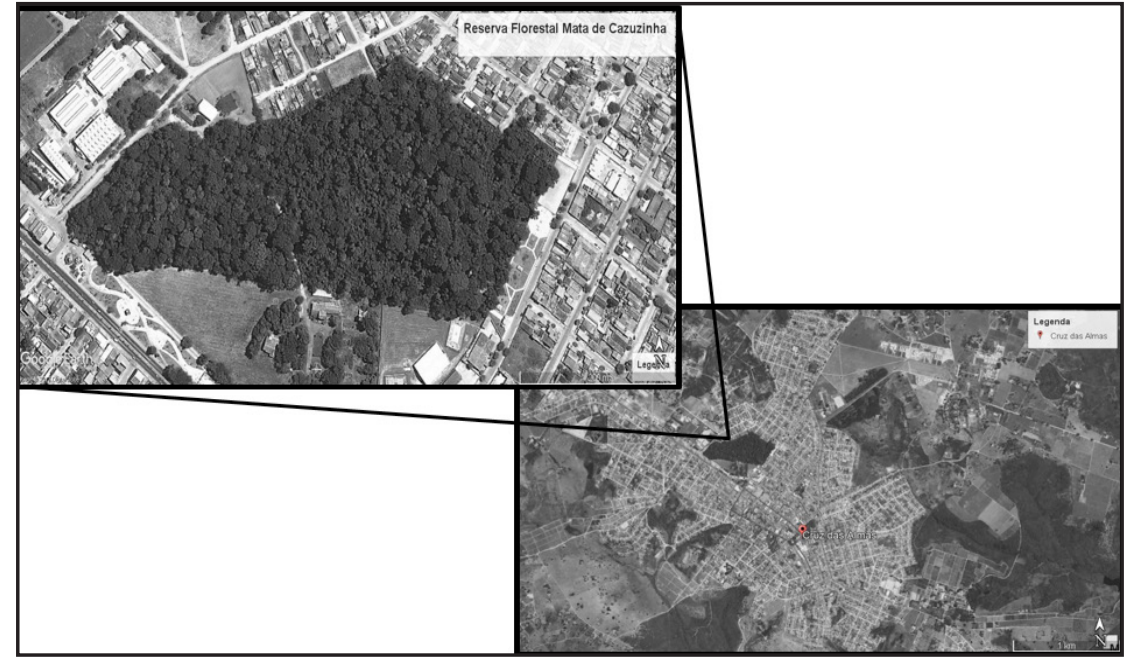

Fonte: Google Earth Pro

situada no complexo urbano da cidade sede do município (Figura 1). Este é um fragmento constituído em área de Preservação Permanente com 13 ha, aproximadamente, e que recentemente teve seu entorno cercado com o objetivo de evitar uma maior destruição deste patrimônio por parte da população que reside nas proximidades.

\subsection{Sujeitos da pesquisa}

O foco da pesquisa foi centralizado na população de moradores do entorno da área protegida. A identidade dos participantes foi mantida em sigilo e os mesmos foram identificados com a letra " $m$ ", inicial de morador, seguida do número sequencial em que ocorreram as entrevistas $(\mathrm{m} 1, \mathrm{~m} 2, \mathrm{~m} 3, \ldots, \mathrm{m} 32)$. É importante destacar que a mesma população foi descrita no perfil socioeconômico em estudo anteriormente realizado pelo grupo PET - Programa Educacional Tutorial Conexões de Saberes Socioambientais.

\subsection{Coleta e análise dos dados}

O estudo foi realizado através de pesquisa exploratória. Esse tipo de abordagem permite a obtenção e descrição de dados com perfil quali-quantitativo do objeto de estudo, além de possibilitar ao pesquisador, conceituar as inter-relações entre as propriedades do fenômeno e o ambiente observado (MARCONI e LAKATOS, 2003). Este tipo de interpelação, também denominado em algumas situações como estudo de caso, permite pesquisar e conhecer os fenômenos a partir da ótica individual ou coletiva, e suas formas de organizações mais diversas (YIN, 2001).

Para avaliar a percepção dos moradores em relação à caça, realizou-se um levantamento através de aplicação de questionário semiestruturado, composto de perguntas objetivas (fechadas) e subjetivas (abertas), além de entrevistas não estruturadas e observações de campo (Quadro 1). As perguntas subjetivas onde as respostas foram livres permitiram uma avaliação do censo crítico dos entrevistados em relação à caça.

Quadro 1 - Questionário aplicado à comunidade de moradores do entorno da Reserva Florestal Mata de
Cazuzinha, Cruz das Almas, Bahia.

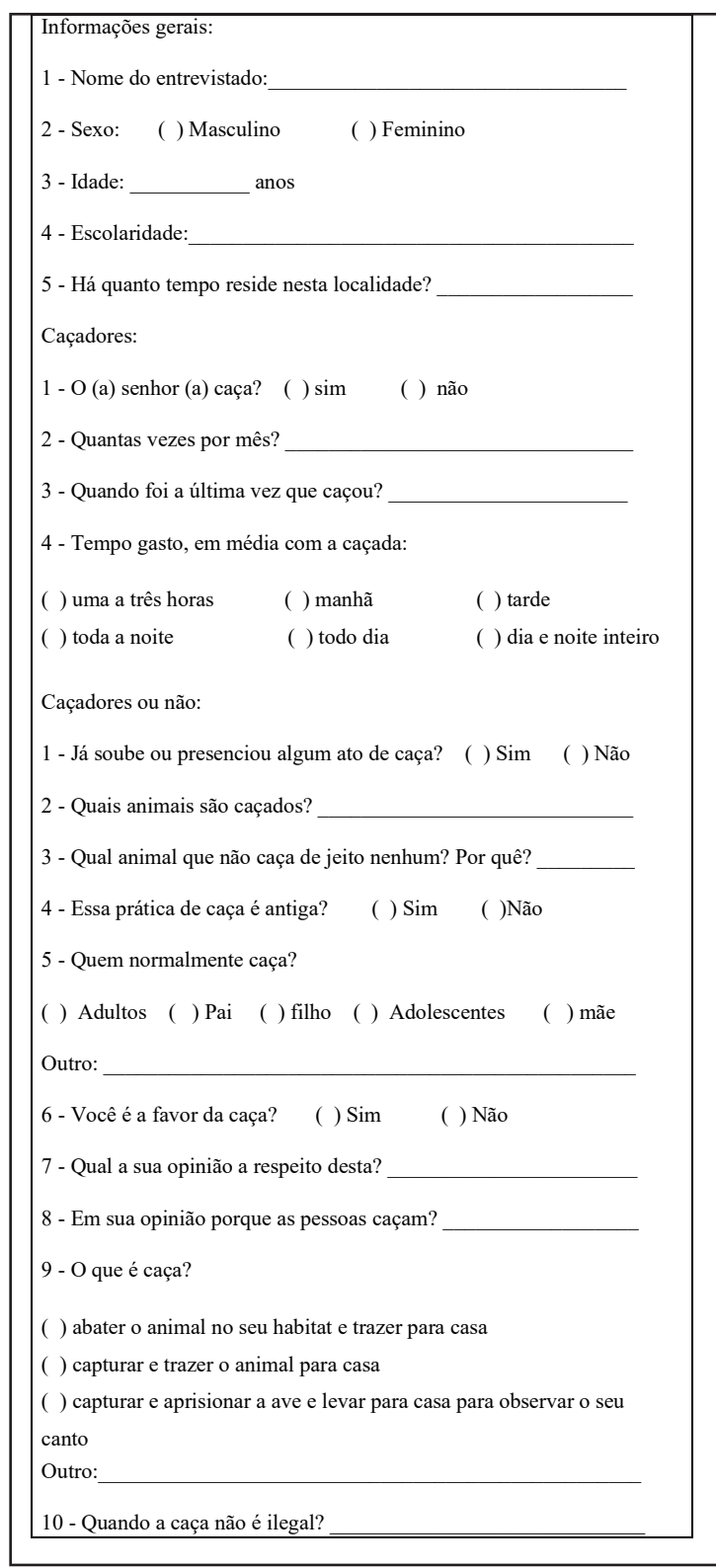


A coleta de dados ocorreu entre os meses de abril e maio de 2013. Os dados alusivos às questões abertas foram analisados, segundo Bardin (1977) através de observação de conteúdo categorial temática. Essa abordagem corresponde a métodos de dados qualitativos, que inicialmente se configura pela identificação nos textos, agrupando as respostas dos indivíduos pesquisados às questões subjetivas, de acordo com a temática específica. Além disso, ainda seguindo Bardin (1977), realizou-se análise de discurso, o que permitiu a organização e interpretação das informações.

\section{Resultados e Discussão}

A faixa etária do recorte amostral entrevistado variou entre 10 e maiores de 60 anos de idade, sendo que destes, $63 \%$ eram do sexo feminino e $37 \%$ do masculino. Com relação ao tempo de residência no entorno da unidade de conservação (UC), $31 \%$ reside em tempo inferior ou igual há oito (08) anos, $28 \%$ reside em tempo inferior ou igual há dezesseis (16) anos e $41 \%$, reside em tempo igual ou superior dezessete (17) anos. Quanto ao grau de instrução de formação, $6 \%$ possuem ensino fundamental incompleto, $19 \%$ possuem ensino fundamental completo, $34 \%$ possuem ensino médio completo ou incompleto, $41 \%$ completaram ou não o ensino superior.

Mediante a coleta dos dados, observou-se que os entrevistados disseram não promover atividades referentes à caça e captura de animais na Mata de Cazuzinha. Ainda, com relação ao histórico dessas atividades de caça, $75 \%$ dos entrevistados responderam que nunca soube ou presenciou atos de caça na Reserva, enquanto que $25 \%$ já presenciaram ou ouviram falar de tal atividade, sendo que deste total de entrevistados, $87,5 \%$ é do sexo masculino. $\mathrm{O}$ tempo de residência na localidade é em média de 19 anos.

Questionados sobre desde quando as caças ocorrem, $75 \%$ dos entrevistados afirmaram se tratar de uma atividade antiga no local. Nesse contexto, ao considerar o tempo médio em que esses moradores residem no entorno da mata (19 anos) e o período de regulamentação da UC (2009), percebe-se que parte da riqueza biológica do local se perdeu desde o contato com os primeiros moradores a fixaram residência no entorno da mata (TOWNSEND; BEGON; HARPER, 2010). Assim, observa-se que até a instituição da área como uma UC a caça acontecia indiscriminadamente sem nenhum processo de assistência do poder público.

Os danos à integridade desse remanescente de Mata Atlântica são evidentes, decorrentes de constantes pressões antrópicas, tais como: a expansão habitacional desordenada e a diminuição consequente da área de floresta e a deposição de lixo gerado pelas residências do entorno. Aliada a estas perturbações, as caçadas apresentam-se como a principal justificativa para a perda ampla da diversidade biológica, sobretudo as espécies da fauna de vida terrestre (mamíferos e répteis, etc.). A escassez de fauna, por sua vez, diminui a probabilidade de êxito na investida (caçada), e esta tendência explica a indicação dos entrevistados de que a caça já não representar uma atividade do cotidiano dos moradores do entorno da Mata.
Quanto ao perfil das pessoas que promovem a caça. Perguntada sobre "quem normalmente caça?", $40 \%$ dos entrevistados, responderam serem os autores de tal prática, os jovens e adultos, e do sexo masculino. Santos et al. (2015) em seu estudo sobre tipologias biofílicas na percepção sobre a caça em uma comunidade rural, observou que a prática da caça, em sua maioria, é realizada pelo sexo masculino.

Todos os entrevistados responderam não ser a favor da caça, salvo quando esta se mostrar necessária à sobrevivência da família. Neste sentido, observa-se que a percepção dos moradores relaciona-se ao pensamento de preservação dos animais que ainda habitam a área da reserva, no entanto, legitimam a atividade em casos de necessidade ou de vulnerabilidade social. Este comportamento demonstra a articulação e coexistência de um posicionamento preservacionista e de visão ecocêntrica e ao mesmo tempo de uma visão antropocêntrica sempre defendida por meio de justificativas (neste caso, a necessidade da caça para a sobrevivência das famílias dos caçadores). Santos et al. (2015) verificaram em sua pesquisa que os entrevistados também detinham o mesmo pensamento apresentado nesse estudo, que a caça é altamente justificada e adquire cunho legal quando é para atender à necessidade alimentar de quem a está praticando. Os autores ainda ressaltaram que a percepção sobre a caça por parte dos moradores da comunidade foco da pesquisa, é envolta de aspectos éticos comportamentais, vinculados à cultura local.

Os entrevistados apresentaram variadas concepção a respeito da caça. Do total de 32 moradores interpelados, $55 \%$ afirmaram que caça, corresponde a abater o animal no seu habitat e transportá-lo para casa. Já $24 \%$ disseram ser a captura e aprisionamento de aves para observar/ desfrutar do seu canto e outros $21 \%$ consideram a caça o ato de capturar e trazer para casa, todo e qualquer tipo de animal. Pode-se compreender que a variação de conceitos sobre a caça pode estar relacionado com a cultura local que, arraigadamente aceita a captura de animais, (especialmente de aves), mesmo que isso se traduza em perdas de vida animal, seja por dificuldades de captura, seja por verdadeiro propósito de abater as mesmas.

Neste sentido, a maioria que desconsideram a captura de animais vivos como sendo caça, justificam o aprisionamento desses animais. Mesmo a totalidade dos entrevistados posicionando-se contra as caçadas, sua compreensão limitada sobre a atividade (ao não considerar captura de animais vivos como caça), sinaliza para a banalização desta atividade. Principalmente quando referem-se a captura de aves.

Segundo as informações sobre "quais animais são caçados": pássaros foram citados por $55 \%$ dos entrevistados; seguidos dos micos com 18\%; o teiú, cobras e raposas são mencionados em $9 \%$ dos respondentes, cada. Quando questionados sobre "qual animal que não é caçado de jeito nenhum?” foi respondido pela maioria que "só aqueles que não existem no interior da Mata", deixando subentendido que qualquer animal estaria passivo de ser caçado, em algum momento. A afirmação de que "só não caçamos aqueles que não existem mais por aqui" ratifica a inexistência de empatocentrismo ${ }^{1}$, sugerido por (WILSON, 2002, p. 153).

No contexto destes resultados, deve-se concordar com 
Tabela 1 - Concepções do termo "opinião a respeito da caça" por moradores do Reserva Florestal Mata de Cazuzinha, Cruz das Almas, Bahia.

\begin{tabular}{|c|c|c|}
\hline Categoria & Depoimentos & Moradores $\mathrm{n}^{\circ}(\%)$ \\
\hline $\begin{array}{l}\text { Motivos } \\
\text { sentimentais / } \\
\text { psicológicos / } \\
\text { emocionais }\end{array}$ & 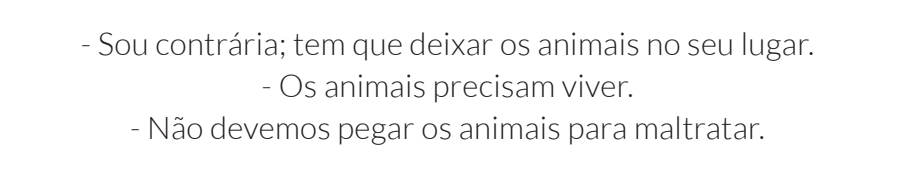 & $5(21)$ \\
\hline Porque é ilegal & $\begin{array}{l}\text { - Extinção dos animais que tem o direito da liberdade. } \\
\text { - Todo ser vivo tem direito a liberdade. } \\
\text { - Não se deve caçar de jeito nenhum. }\end{array}$ & $3(13)$ \\
\hline $\begin{array}{l}\text { Por questões } \\
\text { ecológicas }\end{array}$ & $\begin{array}{l}\text { - Faz parte do nosso ecossistema e não é para ser caçado, existem } \\
\text { outros meios de comércio. } \\
\text { - Quanto mais caça, mais entra em extinção. } \\
\text { - A fauna brasileira já está muito devastada. }\end{array}$ & $7(29)$ \\
\hline É contra essa cultura & - Na maioria das vezes se caça por uma cultura, por diversão. & $1(4)$ \\
\hline Não explicou & $\begin{array}{l}\text { - Sou contra, totalmente. } \\
\text { - Deve ser evitado. } \\
\text { - A caça de animais da natureza não. }\end{array}$ & $8(33)$ \\
\hline
\end{tabular}

Fonte: Dados da pesquisa

Ferreira et al. (2007) quando afirmam que as espécies a serem caçadas, as técnicas utilizadas e o motivo, são todos aspectos essenciais para o entendimento de como se utiliza essa caça e nível de severidade desta ação sobre as espécies silvestres. Para Bennett e Robinson (1999), as mais variadas dimensões culturais de cada população impactam em diferentes escalas a fauna silvestre. Principalmente nos lugares de florestas tropicais, estes animais são para diversos usos, desde alimentação, atividades culturais, até comércio de animais vivos, dentre outros fins.

Conforme apresentado na tabela 1 , todos os entrevistados demonstram ser contrários às atividades da caça. No entanto, desse universo, 8 não justificaram esse posicionamento. Além disso, percebe-se certa contradição, quando questionados anteriormente sobre quais animais não devam ser caçados a maioria afirma ser apenas aqueles que não são mais encontrados na Mata.

Quando questionados sobre a prática da caça, todos os entrevistados não se manifestaram a favor do ato. No entanto, as motivações relatadas foram diversas, sendo abordadas tanto motivações relacionadas ao fator emocional quanto posicionamentos referentes à consciência ecológica, assim como observada no estudo realizado por Santos et al. (2015). Fatores tais como esses e ainda outros, como, por exemplo, os sentimentais e o psicológico devem ser trabalhados em projetos de educação ambiental, o que promoveria a discussão pela preservação do ambiente e de seus componentes de forma abrangente e pluralista.

${ }^{1}$ Empatocentrismo: onde se julga que os direitos intrínsecos ao homem, devem ser estendidos a cavalos, cães, chimpanzés e outros animais inteligentes com os quais sentimos certo grau de empatia. Ou seja, segrega as espécies de acordo com a própria afinidade.
Fator ligado ao lado emotivo ou sentimental das pessoas, em se tratando da caça animal, encontra-se relacionada à convicção de que o meio natural está constituído de uma formação harmônica e espiritual que tende a resguardar as características singulares da natureza (SANTOS; MACHADO, 2006, p. 318).

Analisando os dados referentes à tabela 2 , observamos que a maioria dos moradores vizinhos à reserva, caracterizam a caça como ato ilegal, independentes dos fatores condicionantes, uma vez que metade dos entrevistados consideram toda a caça como um ato ilegal, seguido de $41 \%$ que condicionam a ilegalidade da caça, a fatores tais como, o método, a necessidade de quem pratica as caçadas, o grau de ameaça de extinção dos animais caçados, etc.

Nesse contexto, parece cabível à administração pública o papel de traçar estratégias que venham informar à população adjacente sobre a importância da preservação da diversidade biológica local, planejando atividades que venham a despertar nas pessoas uma nova visão a respeito da preservação da fauna da Mata de Cazuzinha. Mas, as informações levantadas sobre o ato de caça, indicam que não há mais ocorrência desse tipo na mata. Justamente pelo fato de as caçadas serem atividades históricas na reserva, o que promoveu o desaparecimento da fauna local.

A maioria dos respondentes apontou mais de uma razão que condiciona o ato de caça (tabela 3). Entre todas as respostas referentes à motivação das pessoas á cometerem o ato de caçar, $41 \%$ dos indivíduos alvo dessa pesquisa apontaram a diversão como principal razão e $36 \%$ dos entrevistados declaram a realização da prática devido a necessidade (seja por alimento ou 
Tabela 2 - Concepções do termo "quando a caça não é ilegal" por moradores do Parque Florestal Mata de Cazuzinha, Cruz das Almas, Bahia.

\begin{tabular}{|c|c|c|}
\hline Categoria & Depoimentos & Moradores $\mathrm{n}^{\circ}(\%)$ \\
\hline Toda caça é ilegal & $\begin{array}{c}\text { - Nenhum ato de caça é "legal”. } \\
\text { - Qualquer tipo de caça é ilegal. } \\
\text { - Não existe caça legal. }\end{array}$ & $16(50)$ \\
\hline $\begin{array}{l}\text { Quando autorizada pelo } \\
\text { órgão oficial }\end{array}$ & $\begin{array}{l}\text { - Quando há o controle das espécies caçadas (caça em } \\
\text { estabelecimento). } \\
\text { - Quando há autorização dos responsáveis pela } \\
\text { preservação animal. } \\
\text { - Qualquer tipo de caça é ilegal a não ser quando para } \\
\text { controle da população. }\end{array}$ & $6(19)$ \\
\hline Quando é por necessidade & $\begin{array}{l}\text { - Quando abatemos para sobrevivência. } \\
\text { - Quando se aprisiona para venda deveria ser permitido, } \\
\text { pois é uma forma de trabalho. } \\
\text { - Quando se mata em zona rural e tem animais que podem } \\
\text { ser usados para alimentação. }\end{array}$ & $7(22)$ \\
\hline Quando gera prejuízos & $\begin{array}{l}\text { - Quando tem uma grande reserva da espécie e que não vá } \\
\text { causar mal a mesma. }\end{array}$ & $1(3)$ \\
\hline Outro & $\begin{array}{l}\text { - Depende do animal, aqueles que estiverem em falta, é } \\
\text { ilegal. } \\
\text { - Só quando mata é ilegal. }\end{array}$ & $2(6)$ \\
\hline
\end{tabular}

Fonte: Dados da pesquisa

Tabela 3 - Concepções do termo "por que as pessoas caçam" por moradores do Parque Florestal Mata de Cazuzinha, Cruz das Almas, Bahia.

\begin{tabular}{|c|c|c|}
\hline Categoria & Depoimentos & Moradores $\mathrm{n}^{\circ}(\%)$ \\
\hline Diversão & $\begin{array}{l}\text { - Por hobby } \\
\text { - Por necessidade, tráfico, diversão. } \\
\text { - Muitas vezes para sobrevivência, esporte, lazer. }\end{array}$ & $20(43)$ \\
\hline Necessidade & $\begin{array}{c}\text { - Por falta de atividade. } \\
\text { - Por alimento. } \\
\text { - Para vender, outros, para se alimentar. } \\
\text { - Algumas por diversão outras para suprir as suas } \\
\text { necessidades. }\end{array}$ & $17(36)$ \\
\hline Vício/prazer/cultural & $\begin{array}{l}\text { - Por "gosto". } \\
\text { - Muitos por necessidade e outros por prazer e falta de } \\
\text { consciência. }\end{array}$ & $4(8)$ \\
\hline Contemplação & $\begin{array}{l}\text { - Existem pessoas que gostam de capturar para deixar os } \\
\text { animais presos. }\end{array}$ & $1(2)$ \\
\hline Comercialização & $\begin{array}{c}\text { - Uns para vender... } \\
\text { - Por instinto, antes as pessoas caçavam para venda, para } \\
\text { o tráfico. }\end{array}$ & $5(11)$ \\
\hline
\end{tabular}

Fonte: Dados da pesquisa 
meio de ganhar dinheiro para o sustento de si próprio e família). Apesar dos estudos serem realizados em ambientes distintos, os aspectos aqui levantados sobre a caça animal convergem em vários pontos discutidos por Santos et al. (2015), uma vez que ao se tratar de pessoas, muitos hábitos comportamentais se constituem em legados dos antepassados, que em algum momento da história, também absorveu o comportamento de outrem, e assim, mesmo sendo comunidades separadas geograficamente, seu modo de pensar e agir, uma vez que sofrem de várias influências, pode se assemelhar perante algumas situações. Outras razões foram relatadas, tais como: contemplação, comercialização, razões culturais, dentre outras.

$O$ fato é que nunca houve uma intervenção por parte das autoridades responsáveis pela fiscalização ambiental da reserva, que pudesse promover a conscientização dos caçadores a respeito dos malefícios causados ao ambiente por parte da caça indiscriminada. Pelo fato de da área apresentar uma redução drástica no contingente de animais a serem caçados na Mata de Cazuzinha, perdeu-se por parte da população vizinha, a cultura de realização desta atividade antes praticada regularmente. Com isso, ainda é natural observar nas falas dos entrevistados, discursos que defendem a caça, mesmo que esta não esteja mais acontecendo nas mediações da reserva, em decorrência do desaparecimento das espécies que habitavam naturalmente o local, sobretudo os animais de hábitos terrestres.

\section{Considerações finais}

O estudo da percepção ambiental é de fundamental importância para que possamos compreender melhor as inter-relações entre o homem e o ambiente, suas expectativas, anseios, satisfações e insatisfações, julgamentos e condutas. Os resultados deste trabalho permitem demonstrar que na percepção dos moradores do entorno da Mata de Cazuzinha, as atividades relacionadas à caça de animais silvestres é algo que devesse ser repensado, apesar dos incipientes relatos de atos deste tipo na Reserva.

Pelos dados apresentados, demonstra-se que a comunidade do entorno considera a atividade de caça antiga e que esta, apresenta-se enraizada culturalmente ao local. Fato este complementado por esta atividade vir perdendo intensidade apenas na medida em que as populações faunísticas vêm diminuindo (e não por razões ligadas a preservação dos componentes biológicos da Mata). Neste contexto, secundariza-se que a destruição da fauna local compromete as interações bióticas e abióticas que garantem a preservação de ambientes como esse, e que sua manutenção exerce enorme influência na qualidade de vida da população do entorno.

A falta de supervisão e fiscalização que reprima a destruição de habitats, em conjunto com a insuficiência das abordagens da educação ambiental, deixa clara a necessidade de maiores investimentos por parte do poder público, na tentativa de instrumentalizar os órgãos de meio ambiente em ações de cumprimento das normativas legais, assim como de educação e reeducação da popu- lação, para a conservação dos recursos naturais. Esta provável mudança no comportamento das pessoas poderia ser plausível com a inserção de projetos específicos nas instituições escolares locais, simultaneamente com campanhas persuasivas de mudança de comportamento da população em geral, no intuito de sensibilizá-la para o comprometimento com a sustentabilidade da vida nas suas mais variadas formas.

A partir dos resultados deste estudo demonstra-se que os entrevistados, na maioria das vezes, percebem os animais baseando-se em aspectos afetivos, estando tal comportamento visível em seus posicionamentos contrários ao ato de caça, onde estes vinculam tal ato, ao risco de extinção dos animais pertencentes ao nicho ecológico da reserva mata de Cazuzinha. Embora, em determinados questionamentos as percepções observadas tenham perdido completamente esse sentimento de proteção aos animais, principalmente quando é relatado por alguns moradores que os animais que não estão passivos de sofrerem investidas de caça são apenas o que não podem ser mais encontrados na região.

É notório que as pessoas demonstrem um ponto de vista, por vezes restritas e/ou limitada com relação à importância da fauna local, sendo, portanto, de suma importância uma educação ambiental continuada, para além dos muros da escola. Percebe-se que a falta de desenvolvimento de projetos voltados à conscientização dos moradores há anos, de certo influenciou negativamente na exploração da fauna local.

Nesse sentido, tentou-se mapear os pensamentos dos moradores locais, com relação às práticas de caça animal, no intuito de sensibilizar a população local acerca desta problemática e levar aos seus conhecimentos as possíveis ferramentas legais que lhes auxiliariam na manutenção dos ecossistemas.

\section{Agradecimentos}

Ao Programa de Educação Tutorial Conexões de Saberes Socioambientais, pela concessão da bolsa de estudos; aos moradores do entorno da Reserva Florestal Mata de Cazuzinha, Cruz das Almas, BA, por tornar possível o desenvolvimento deste projeto de pesquisa.

\section{Referências}

BARDIN L. Análise de conteúdo. 70th ed. Lisboa: Edições; 1977.

COSTA RGS, COLESANTI MM. A contribuição da percepção ambiental nos estudos das áreas verdes. Ra'e Ga. 2011;22:238-251.

DEL RIO V. Cidade da mente, cidade real: percepção e revitalização da área portuária do Rio de Janeiro. In: Del Rio V, Oliveira L, editors. Percepção Ambiental: a experiência brasileira. São Carlos: Studio Nobel: UFSC; 1999. P. 3-22. 
FAGGiONATO S. Percepção ambiental. 2007. Disponível em: <http://educar.sc.usp.br/biologia/textos/m_a_txt4. html>. Acesso em: 20 mai. 2018.

FERREIRA DSS, CAMPOS CEC, SÁ-OLIVEIRA JC, ARAÚJO AS. Atividades de caça de animais silvestres no assentamento rural Nova Canaã, Amapá, Brasil. In: Anais do 8 Congresso de Ecologia do Brasil [Internet]; 2007 Setembro 23-28; Caxambu, Minas Gerais, Brasil. 2007 [cited $2017 \mathrm{dez}$ 15]. Available from: https://www.researchgate. net/publication/237530818_ATIVIDADES_DE_CACA_ DE_ANIMAIS_SILVESTRES_NO_ASSENTAMENTO_ RURAL_NOVA_CANAA_AMAPA_BRASIL

GEERTZ C. A interpretação das culturas. 2nd ed. Rio de Janeiro: Guanabara Koogan S.A.; 1989.

IBGE. INSTITUTO BRASILEIRO DE GEOGRAFIA E ESTATÍSTICA [Internet]. Estimativas da população residente no Brasil e unidades da federação com data de referência em $1^{\circ}$ de julho de 2016 [cited 2017 set 28]. Available from: ftp://ftp.ibge.gov.br/ Estimativas_de_Populacao/Estimativas_2016/estimativa_ dou_2016_20160913.pdf.

MARCONI MA, LAKATOS EM. Fundamentos de metodologia científica. 5th ed. São Paulo: Atlas S.A.; 2003.

NASCIMENTO MD, SOUZA BSP. Fragilidade ambiental e expansão urbana da Região Administrativa Nordeste da sede do município de Santa Maria, RS. Ciênc. Nat. 2010;32(2):163-181.

BENNETT EL, ROBINSON JG. Hunting for sustainability: the start of a synthesis. In: Robinson JG, Bennett El, editors. Hunting for sustainability in tropical forest. Columbia University Press; 1999. p. 499-519.

ROCHA AA, PEDRO Z, PAVONE AP, MATTOSO A. A Reserva da Biosfera da Mata Atlântica e sua aplicação no Estado de São Paulo. 1st ed. São Paulo: Terra Virgem Editora; 1998.

SANTOS DM, TEIXEIRA MC, MENDEZ JMD, PUGAS AS. Tipologias biofílicas na percepção sobre a caça em uma comunidade rural do recôncavo da Bahia: subsídios à Educação Ambiental para conservação da biodiversidade. RevBEA. 2015;10(2):25-35.

SANTOS VL, MACHADO LMCP. Vínculos topobiofílicos na relação visitantes e paisagens. In: Gerardi LHO, Carvalho PF, organizador. Geografia: ações e reflexões. São Paulo: AGETEO; 2006.

SILVA DDM, SANTOS NRZ, VOGEL HM, WEBER MA. A população da cidade de São Gabriel, RS e o grau de satisfação em relação à qualidade ambiental urbana. Ciênc. Nat. 2016;38(2):847-861.
SIMÕES SS, SILVA LRO, MARTINS MLL. Rubiáceas da Mata de Cazuzinha, Cruz das Almas, Bahia. In: Anais 64 $^{\mathbf{0}}$ Congresso Nacional de Botânica [Internet]; 2013 Novembro 10-15; Belo Horizonte, Minas Gerais, Brasil. 2013 [cited 2018 fev 13]. Available from: http:/www. botanica.org.br/trabalhos-cientificos/64CNBot/resumoins19772-id5521.pdf

TOWNSEND CR, BEGON M, HARPER JL. Fundamentos em ecologia. 3rd ed. Porto Alegre: Artmed; 2010.

TUAN YF. Topofilia: um estudo da percepção, atitudes e valores do meio ambiente. 1st ed. São Paulo: DIFEL; 1980.

WILSON EO. O futuro da vida: Um estudo da biosfera para todas as espécies inclusive a humana. 1st ed. Rio de Janeiro: Editora Campus; 2002.

YIN RK. Estudo de caso: Planejamento e métodos. 2nd ed. Porto Alegre: Bookman; 2001. 